\title{
Road safety assessment in preferential bus lanes through field analysis and microsimulation of traffic conflicts
}

\author{
Evaluación de la seguridad vial en carriles preferenciales para buses por medio del análisis \\ de conflictos de tráfico en campo y microsimulación
}

\begin{abstract}
Julián Darío Otero-Niño', Juan David Heredia-Castiblanco ${ }^{1}$, Paula Daniela Fonseca-Agudelo ${ }^{1}$, Sebastián Cabrera-Pinzón ${ }^{1}$, Alejandro Gómez-Mosquera' ${ }^{1}$ Luis David López-Buitrago' ${ }^{1}$, Francisco Julián Sandoval-Ávila ${ }^{1}$, Miguel Ángel Ospina-Serrano ${ }^{1}$, Jhon Alexander González-Mendoza', Liliana Lyons-Barrera' , Lenin Alexander Bulla-Cruz ${ }^{\text {* }}$

${ }^{1}$ Semillero de Investigación en Infraestructura y Movilidad - SIMUN, Grupo de Investigación en Logística para el Transporte Sostenible y la Seguridad - TRANSLOGYT, Facultad de Ingeniería, Universidad Nacional de Colombia. Carrera 30 \# 45-03. C. P. 111321. Bogotá D.C., Colombia
\end{abstract}

\author{
ARTICLE INFO: \\ Received: September 27, \\ 2018 \\ Accepted: February 07, \\ 2019
}

\section{AVAILABLE ONLINE:}

February 07, 2019

\section{KEYWORDS:}

Driving behavior, urban traffic, surrogate measures, VISSIM, SSAM

Comportamiento en conducción, tráfico urbano, medidas sustitutas, VISSIM, SSAM
ABSTRACT: Preferential bus lanes are a widely use strategy to promote travelers to use public transport instead of private cars. Considering its relevance in the urban transportation planning and operation, it is crucial to evaluate them in terms of the operation and safety externality. We performed a road safety assessment in preferential public transport lanes with complex driving environment using a preventive approach on the $7^{\text {th }}$ Avenue, in Bogota (Colombia), between $39^{\text {th }}$ Street and $45^{\text {th }}$ Street. A detailed study of traffic conflicts was carried out under the guidelines of the Swedish technique, which uses the Time to accident and Conflicting speed to establish the severity of a conflict. A traffic conflict is defined as an incident where, if two road users on collision course maintain their speed and trajectory constant, the crash between them will be imminent. With the field information, we calibrated a VISSIM microsimulation model that correctly replicates its traffic operation. Using the SSAM tool, we validated the base model to identify the simulated traffic conflicts in VISSIM and compared them with the observed conflicts. Under the calibrated environment, we developed and assessed three different scenarios of countermeasures to reduce the number of conflicts observed. As a result, we found that the safest scenario is the one established in the regulations that normalize the operation in preferential lanes, currently not obeyed by most users. Based on our results, we recommend an adjustment in the normative measures, including regulating the stopping time and stopping zones of private vehicles and taxis.

RESUMEN: Los carriles preferenciales para buses son una estrategia utilizada ampliamente para promover que los viajeros utilicen el transporte público en lugar del vehículo privado. Considerando su relevancia en la planeación y operación del transporte urbano, es crucial evaluar estos carriles desde la operación y la seguridad vial. Para lo anterior, se evaluó preventivamente la seguridad vial, en este tipo de carriles, en la Avenida Carrera $7^{\circ}$, en Bogotá (Colombia), entre las Calles 39 y 45 . Se ejecutó un estudio detallado de conflictos de tráfico bajo la técnica sueca, que utiliza el Tiempo al accidente y la Velocidad conflictiva para establecer la severidad de un conflicto. Con la información de campo se validó un modelo de microsimulación en VISSIM, que reproduce correctamente la operación de tráfico. Empleando la herramienta SSAM, fue posible identificar los conflictos de tráfico simulados en VISSIM que, comparados con los observados, permitieron validar el modelo base. Bajo el entorno calibrado, se modelaron tres escenarios diferentes que comprenden propuestas de contramedidas de ingeniería para disminuir el número de conflictos observados.

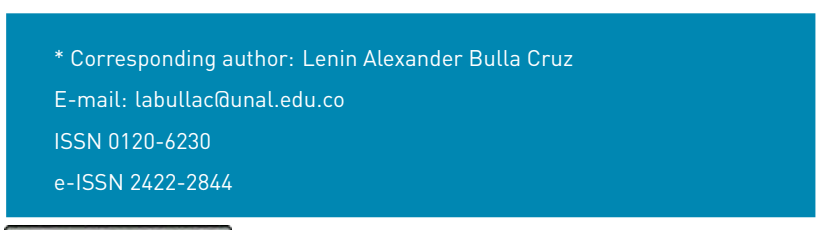


Como resultado, se encontró que el escenario más seguro corresponde al establecido en la normatividad que regula la operación en carriles preferenciales y que, actualmente, no es obedecida por la mayoría de los usuarios. Con base en los hallazgos, se recomienda un ajuste en la normativa, incluyendo la regulación de las zonas y tiempos de parada de los vehículos privados y los taxis.

\section{Introduction}

Globally there are 1.25 million deaths caused by traffic accidents every year [1]. In Colombia, there were more than 46,000 injuries for this cause in 2017. Specifically, public transportation (buses) is responsible for 3,100 of these cases [2], which is a worrying indicator. As a response, governments are turning to policies that encourage safety in public transit.

Bus lanes are a relatively recent alternative in the "push and pull" strategies [3] for promoting travelers to use public transport instead of a private car. Considering the future relevance of such types of lanes in the public transit planning, management, and operations, it is crucial to evaluate them in terms of various components such as operation, safety, environmental externalities among others. In terms of operation, there is a great amount of research developed $[4,5]$. Some literature deal with the definition of different bus lane typologies and the way they operate $[6,7]$. Other studies analyzed improving operation by evaluating some attributes like bus average speed and queue lengths before and after the implementation of these lanes [8]. However, there is limited literature on safety assessment in this kind of infrastructure and they are mainly based on accident-injury data. On the other side, studies of road safety were done at intersections [9], road links [10] or roundabouts [11], among others, but there is still a gap in this assessment type on bus lanes and public transportation.

The research described in this paper consists in the road safety analysis of a preferential bus lane, also known as preferential corridor, using microsimulation with modeling software VISSIM 9 and the Surrogate Safety Measures Assessment Model (SSAM 3.0). This study includes transit and behavioral driver parameters that give major accuracy and certainty to the calibration and validation of the model. The operating conditions and road safety are characterized in a section of the $7^{\text {th }}$ Avenue in Bogota which has a preferential bus lane. The Swedish Traffic Conflicts Technique (STCT) is used to validate the conflict number of observation-based data with microsimulation results through SSAM as a methodology of quantitative risk analysis in road safety, in the infrastructure type described above. Three control countermeasures are proposed to mitigate the risk situations that are detected.

The rest of the paper is structured as follows: First, a literature review of bus lane operation and evaluation of road safety in different traffic interactions, the use of conflicts technique and surrogate safety measures. Then, a description of the study case is presented, including a deep explanation of the bus lane type studied and the theoretical-practical operation conditions. The above is followed by a description of the methodology, detailing the calibration process used. Finally, the results of microsimulation and calibration are presented, including results of three different control countermeasures in hypothetical conditions. The results are discussed in terms of operation and road safety, based on the reduction of the conflicts number and safer surrogate safety measures.

\section{Literature review}

\subsection{Bus lanes}

Different types of bus lanes were developed around the world with particular operational characteristics. Dedicated bus lanes with or without physical barriers are commonly used for BRT systems. The term "intermittent bus lane" was introduced in [6] and defined as a lane which acts as a dedicated bus lane only in presence of buses. In other cases, it is open to mixed traffic. Other authors [12] refer to this as "bus priority", a more general term that involves multiple measures related to a strategy for improving bus operation and enhance environment for users [13]. In this case, operating conditions must be clearly explained at each research study.

In terms of operation of bus lanes, there is a great amount of literature. Different attributes of a corridor with an Intermittent Bus Lane in Lisbon, Portugal, were studied by [8]. They found increases in bus average speed and no significant variation in parameters like other vehicle speeds and queue lengths. In other study [14], a fitting between pre-evaluated data in a Paramics model and after-constructed data on an urban expressway bus lane in Beijing, China, was found. Additionally, they reported improved capacity in the same study area. Other research presents study cases of different cities around the world [15] including operation monitoring [16] and signaling analysis [17], among other topics.

Focusing on road safety dedicated bus lanes, limited literature was found. [18] studied the crash risk between two-wheeler drivers and buses in bus lanes, considering a bodily injury accidents-based risk measure. Furthermore, [19] research about maneuvers to analyze close interactions between bicyclists and buses in bus 
lanes. [20], conducted a study through empirical analysis of accident data, and used an approximation based on microsimulation. A first approach in this field [20], was developed through the implications of an exclusive bus lane. The research was conducted in Melbourne, modelling three scenarios (with AIMSUN) where two of them have an exclusive bus lane and the third one considers mixed traffic. The calibration of this model was based on the two-step calibration model proposed by [21] and used the deceleration rate required to avoid a crash (DRAC) and a crash potential index (CPI) as surrogate measures for assessing road safety.

\subsection{Traffic conflict techniques}

Studies in road safety include estimation of measures that make the assessment possible. Owing to the lack of crash data to apply studies of road safety assessment, researchers have focused on replicate the behavior of drivers with surrogate events. The approximation used in this research are traffic conflicts, which [22] are developed through the Swedish Traffic Conflicts Technique (STCT).

A traffic conflict is defined as an incident where, if two road users on collision trajectory maintain their speed and trajectory constant, the crash between them will be imminent. Based on this concept, there are different physical variables, used as indicators of how close a collision would have happened, as well as the severity of the traffic conflict. Such indicators are known as surrogate safety measures. To avoid the collision, it is necessary that, at least one of the two road users perform an evasive action. The user who first performs this action is called the "relevant user" [9].

As described in [23], many different surrogate safety measures or indicators are used in the road safety assessment. According to [23], the most common measures used are: TTC (time to collision), defined as the time remaining to the collision if the invaded vehicle maintain the speed it currently has. TTC can be calculated in each moment of the risky situation using the speed and the remaining distance to the collision. In the same sense, TA (time to accident) is a critical value of the TTC function that occurs when the invaded vehicle initiates an evasive action; PET (post-encroachment time) is the real time measured between the moment of the trajectory invasion and the moment when the invaded vehicle reaches the eventually collision point, and DR (deceleration rate) is the initial deceleration at the beginning of the conflict. A combination of these measures were used to develop some traffic conflict techniques as "a framework for observed-based safety studies" [23].

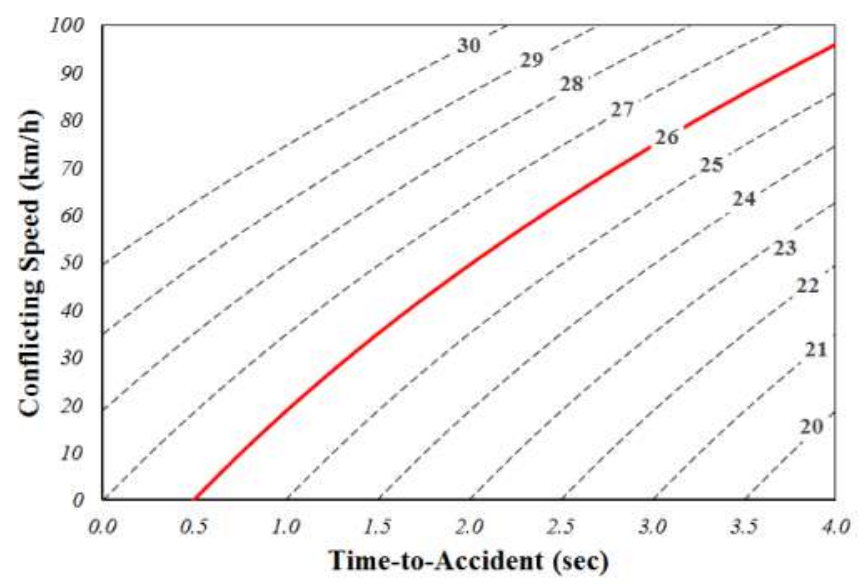

Figure 1 Diagram to estimate the conflict severity [22]

\subsection{The Swedish Traffic Conflict Technique - STCT}

The STCT, first used by [22], estimates the severity of a conflict based on two surrogate measures:

- Time to accident (TA): Time remaining to the collision, foreseen when the relevant user initiates the evasive action.

- Conflicting speed (CS): Speed of the relevant user at the moment when the evasive action starts.

Figure 1 shows the diagram used to distinguish between serious and minor conflicts. Conflicts with severity level 26, or higher, are considered serious; however, there are some indications in the literature that suggests that the limit should be reduced one or two levels minor [24].

This information is collected in the field, through the recurrent observation of videos. The method allows the identification of events that can be considered as conflicts; these are analyzed accordingly using STCT framework, to estimate their severity and then decide if they should be included in the safety assessment.

\subsection{STCT and microsimulation}

The use of simulation models including traffic variables, behavioral parameters and transit operation to assess road safety, using the trajectory files of simulation models through the open tool Surrogate Safety Assessment Model (SSAM), is proposed by [25]. Therefore, SSAM aims to assess traffic safety through the number of simulated conflicts which are complemented with a characterization depending on the severity of some surrogate measures. These indicators are: time to collision (TTC), post 


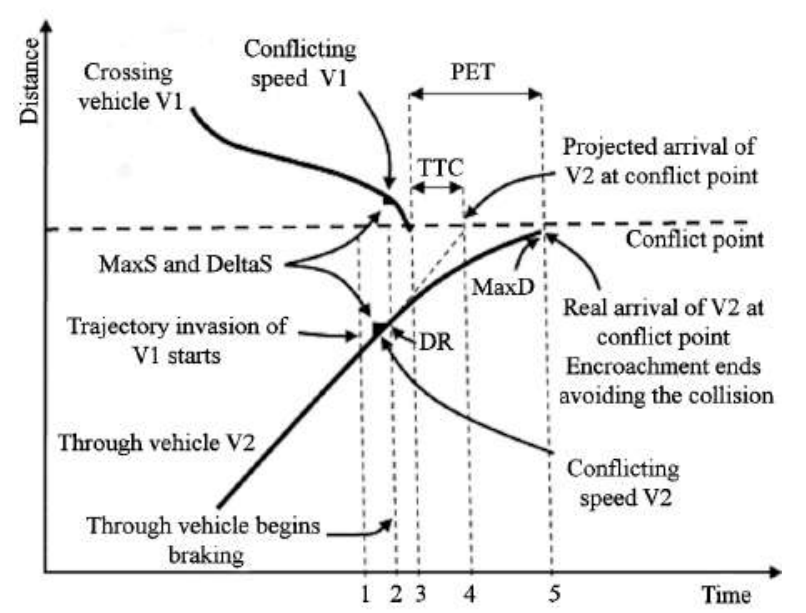

Figure 2 Space-time representation of a traffic conflict and some surrogate measures, adapted from [22]

encroachment time (PET), deceleration rate (DR), maximum speed (MaxS) and speed differential (DeltaS), as shown in Figure 2. These variables are reported by SSAM and their validity depends on the calibration of the simulation model, both by traffic parameters and by conflicts.

\section{Case study}

The study was conducted in a corridor of an important avenue in Bogotá, Colombia, limited to approximately $700 \mathrm{~m}$ length of the road. Two important aspects make attractive this part of the city to be selected for our study: First, it has a preferential bus lane and, second, the sector presented the highest number of reported crash data, from 2014 to June 2018 [26]. The preferential bus lane was implemented in 2014 and consists in an external lane for public transport (buses) with visual segregation through horizontal and vertical signalization, as shown in Figure 3. Private transport can use the preferential lane just in case of right turns to access to intersections or properties. Through observation in situ, it was detected that the road users often use the bus lane in a different way than intended, this is that private vehicles often take up this lane causing a risky operation.

A possible source of traffic conflicts is not only the operation of the preferential bus lane, also the existence of bus stops for different routes and local public transport system's components. Additionally, there are some important elements which made the study area's operation more complex in terms of driving behavior. Such elements are entrances and exits to an educational institute, a hospital, and a gas station, among others. The general location of the study area and roads that currently have a preferential lane are shown in Figure 4. Figure 5 shows the study area with the bus lane the components related to the complex operation, and the location of traffic accidents during the last 5 years. The study period was determined as the hour with the highest number of observed conflicts. The operation was video recorded for 12 continuous hours, during a working day and a Saturday, finding the riskiest period to be from 07:00 to 08:00 on the working day.

\section{Methodology}

The methodology is divided into various steps. In the next section, the development of the base simulation model and the parameters used for its calibration are explained. The first step consists in the development of VISSIM simulation model. The model is carried out to represent the traffic and behavior conditions observed in field, and to evaluate the road safety of the corridor, according to [21]. After that, it is necessary to calibrate the model through some traffic variables as speed and volumes, and through safety variables as traffic conflicts. To validate the model from the point of view of road safety, the STCT is used to identify serious conflicts, in the field, looking for the simulation model to reproduce the operation observed in terms of the simulated conflicts.

Subsequently, the calibrated and validated base model is characterized through traffic and safety variables. Finally, under the calibrated environment, control countermeasures are proposed and simulated, assessing the improvement of road safety.

\subsection{Development of VISSIM simulation model}

The base model was developed in VISSIM 9. The network was modeled based on a satellite image taken from official sources [27]. The network includes a scheme of $7^{\text {th }}$ Avenue from $39^{\text {th }}$ Street to $45^{\text {th }}$ Street; links and connectors which represent real conditions, as shown in Figure 6. The model includes the preferential bus lane and stops for the local public transport system. Figure 7 shows priority rules and conflict areas that were designed and configured to avoid vehicle overlapping that could lead to the emergence of virtual crashes.

The initial model calibration consisted in the comparison between simulated and field-observed traffic variables. We evaluated volumes and speeds [21] to ensure that the simulation model correctly represents the number of vehicles circulating on the network and the speed at which they circulate. In the base model, volumes and free-flow speeds were evaluated by means of the statistical GEH [28]. 

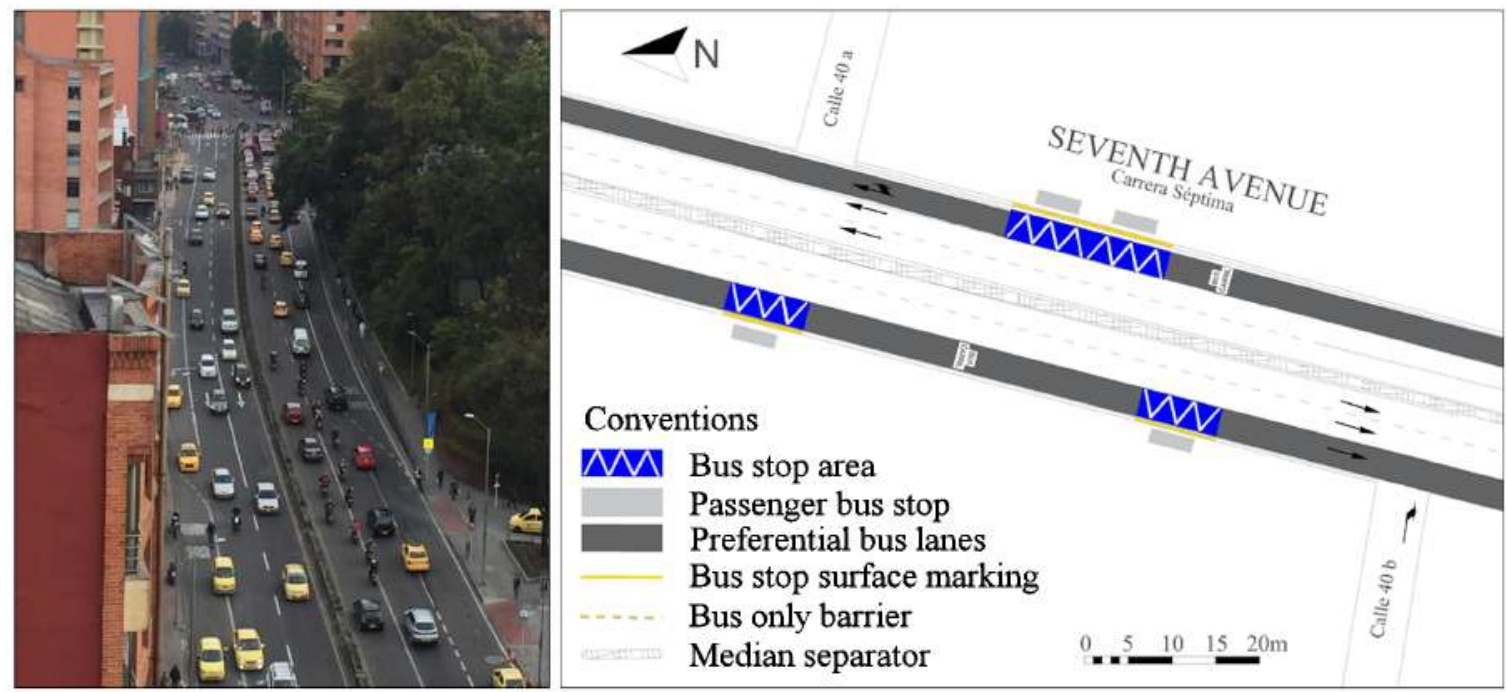

Figure 3 Study site

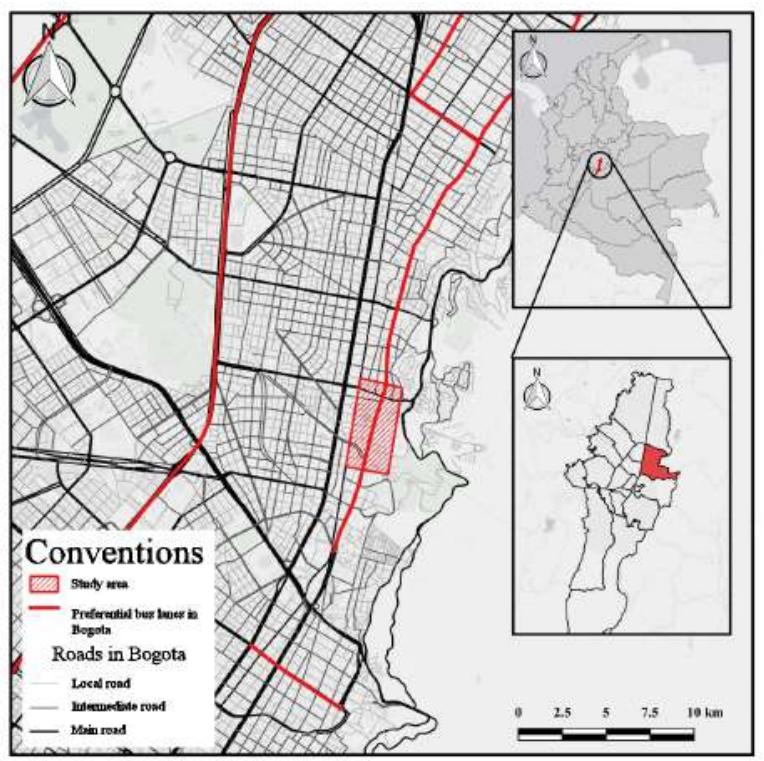

Figure 4 Preferential bus lanes in Bogotá

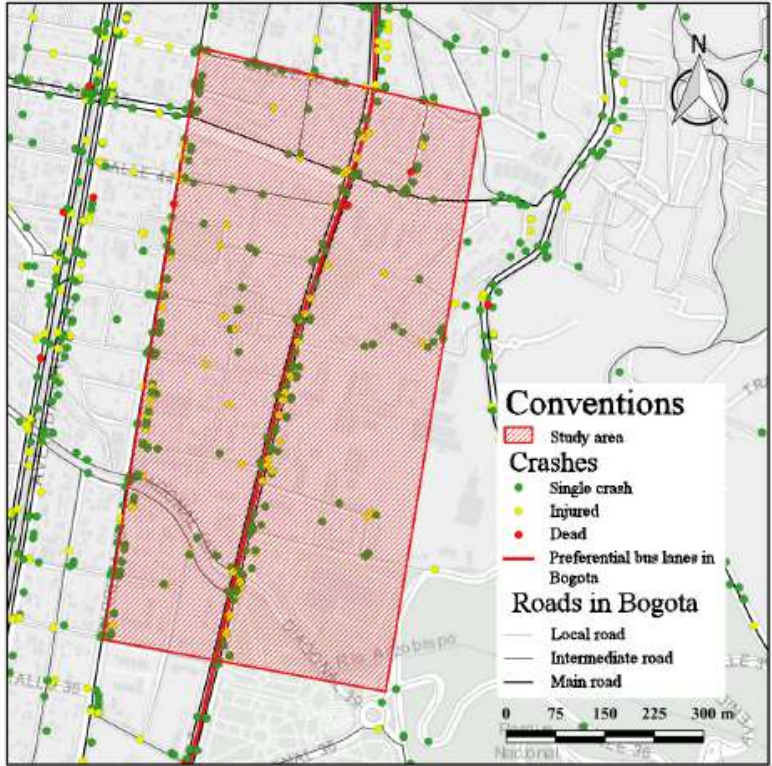

Figure 5 Crash location at the study area
At the end of the second calibration level, the VISSIM software trajectory files are extracted to be used in SSAM. This tool is used to filter simulated traffic conflicts and to obtain their surrogate measures necessary to calibrate the base model. The process has two stages [21]. The first corresponds to the comparison of the observed and simulated number of conflicts, validated by calculating the mean absolute percentage error (MAPE), as is shown in Equation (1)

$$
M A P E=\frac{1}{n} \sum_{i=1}^{n}\left|\frac{c_{m}^{i}-c_{f}^{i}}{c_{f}^{i}}\right|
$$

Where,

$c_{m}^{i}=\quad$ field observed number of conflicts

$c_{f}^{i}=\quad$ simulated number of conflicts

$n=\quad$ number of simulations runs. In this case $n=10$

The initial parameters that are configured in SSAM are TTC, PET and conflict type by angle, as defined in [29]. The initial values by default of TTC and PET are $1.5 \mathrm{~s}$ and $5 s$, respectively. After analyzing the trajectory files, filters are applied to the surrogate measures, according to field observations to calibrate and validate the number of conflicts. The filters are defined in this order: TTC, PET, 


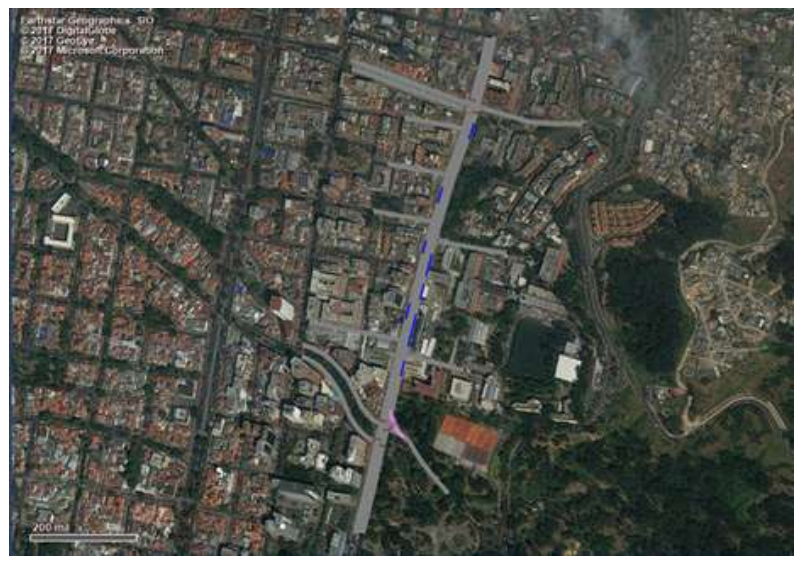

Figure 6 Network built in VISSIM 9

$\mathrm{DR}$ and MaxD. If the expected results are not obtained, behavior parameters of the model are adjusted, until reaching validation criteria.

\subsection{Control countermeasures proposed}

Once the base model is validated, different scenarios are proposed and modeled trying to improve road safety. Three possible operating scenarios are proposed as engineering countermeasures for the better operation of the studied preferential bus lane. The first scenario imposes a strict application of the regulations [30]. Private cars are forced to avoid the bus lane, and only used them on the cases explained previously. The second scenario includes a barrier for the same bus lane, a physical segregation with an open space only at the bus stops to allow overtaking. In Madrid (Spain) there are segregated bus lanes, as shown in Figure 8, with an operation similar to the proposed scenario.

For the third scenario, the proposal is totally different. In this case, a physically segregated internal lane is recommended, which imply left ascending and descending of passengers. Figure 9 shows the scheme for this scenario.

\section{Results and discussion}

\subsection{Calibration results}

As mentioned above, the calibration and validation are reached based on three parameters: speeds, volumes and traffic conflicts. Free-flow speeds were measured in field for each type of vehicle: Taxis, light duty cars, buses and motorcycles. The statistical parameter used to validate the model was the GEH index, whose results are satisfactory when GEH < 5 at least in the $85 \%$ of the screen lines, for urban areas and a count comparison at individual turning

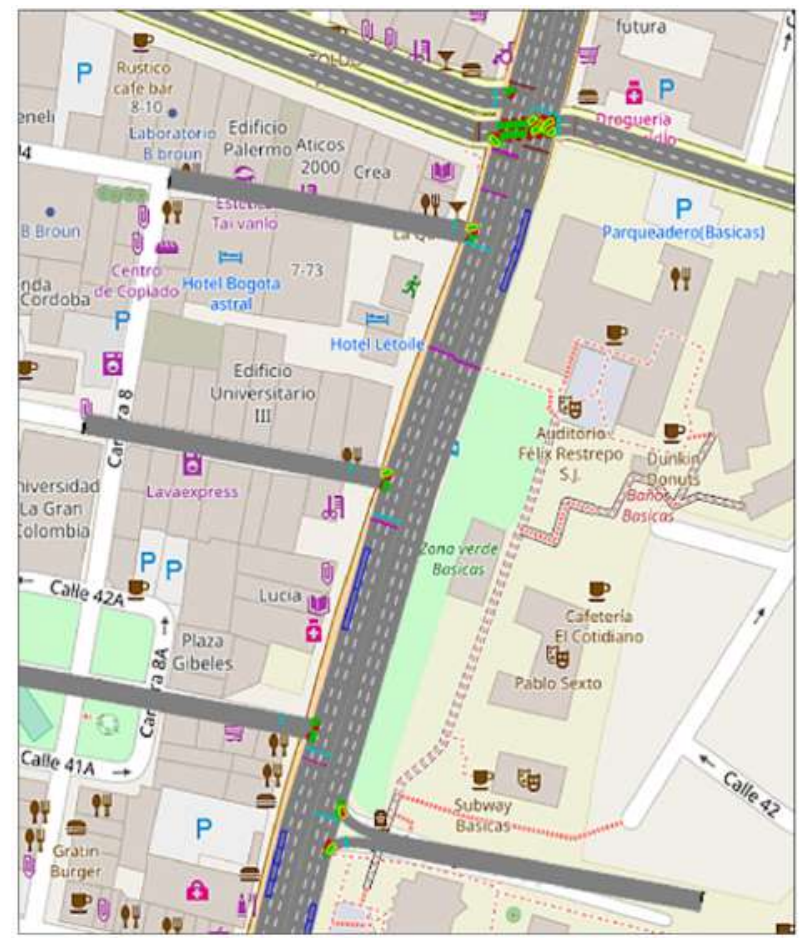

Figure 7 Network built in VISSIM 9

Table 1 GEH statistical for free-flow speeds

\begin{tabular}{cccccc}
\hline & \multicolumn{5}{c}{ Vehicle type } \\
\cline { 2 - 6 } Point & Car & Bus & Taxi & Truck & Motorbike \\
\hline 1 & 2.51 & 2.10 & 1.84 & 1.23 & 2.17 \\
2 & 2.57 & 2.17 & 1.95 & 1.11 & 1.80 \\
\hline
\end{tabular}

movements and / or directional link counts [28]. Free flow speeds were calculated in the model using the data collection point option in two points of the road where free flow speeds were expected to occur. Comparison with field-measured speeds allowed the calculation of the GEH statistical. Results are shown in Table 1. On the other hand, GEH statistical was computed for volumes of fifteen different specific vehicle types. Results were obtained for eight control points in the corridor, each one for four time periods between 07:00am, 07:15, 07:30, 07:45 and 08:00, getting $480 \mathrm{GEH}$ statistical values. Only 16 of those were values above 5 , which was the accepted threshold found in the literature. This reveals a $96.7 \%$ of fitting values for the GEH statistical calibration.

\subsection{Scenarios comparison}

Comparing the base scenario with the three-proposed safety improved scenarios, two operational variables (latent demand and queues) and two road safety-related variables lamount of traffic conflicts and surrogate safety measures), are discussed. Evaluation of operational variables is important in this context, given that we aim 

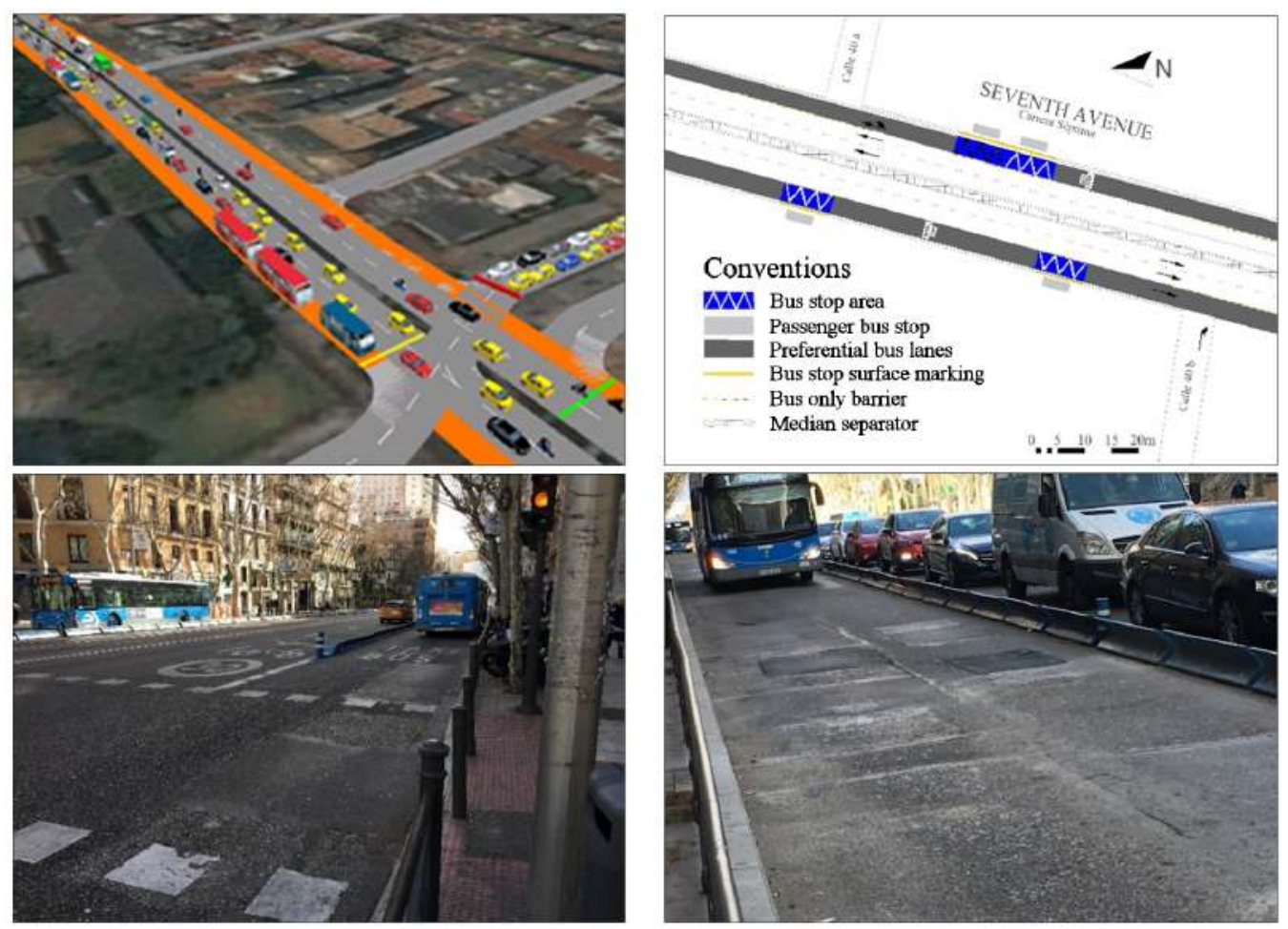

Figure 8 Scheme for scenario 2, physical segregation in external lane
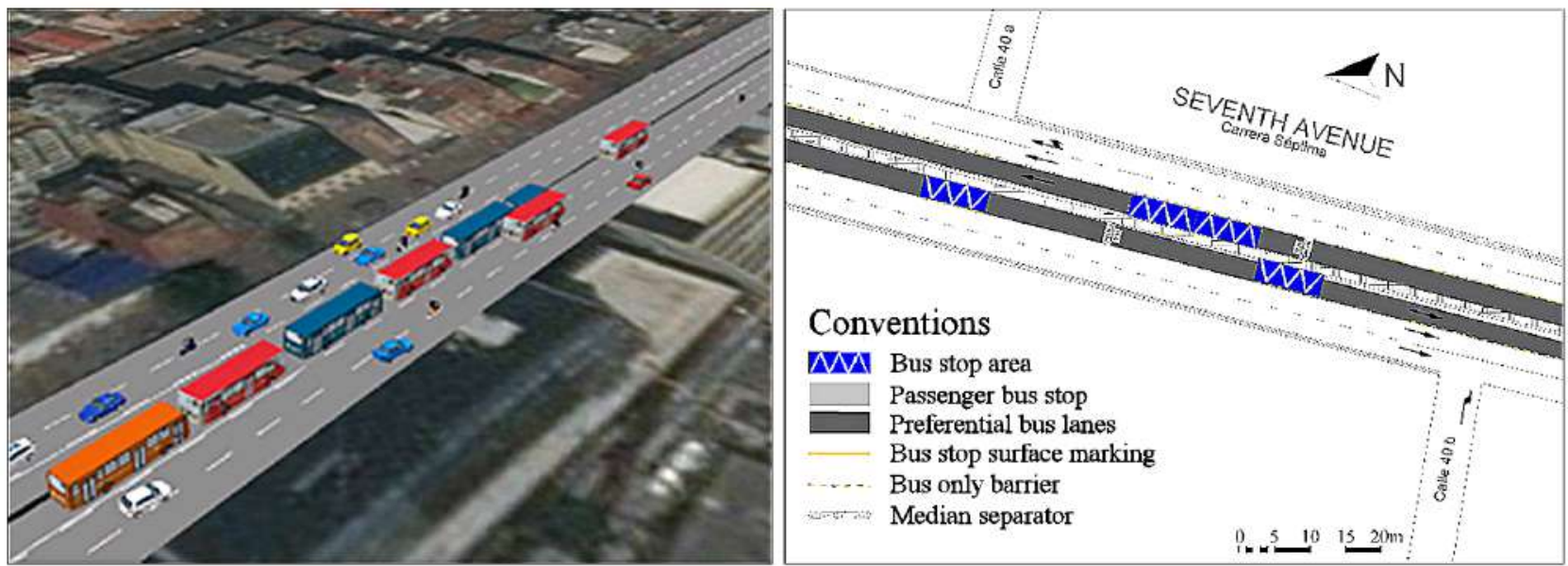

Figure 9 Scheme for scenario 3, physical segregation at internal lane

to improve road safety without negatively affecting the operation.

\section{Latent demand}

The latent demand is calculated in control points where the main inputs and outputs affect the operation of the network. These points correspond to the approaches of the main intersections ( $39^{\text {th }}$ and $45^{\text {th }}$ Streets), before the traffic lights. The latent demand remains the same in the W-E and E-W directions, because those are not affected by the bus lane operation.

When considering S-N direction, we report an increase in latent demand in scenario 3, at both intersections, which is maintained throughout the study hour. On the other hand, the N-S direction presents a slightly different behavior. When vehicles approach from $45^{\text {th }}$ Street, capacity decreases along time in the proposed scenarios. However, the latter occurs much more in scenario 3. The number of vehicles going south from $39^{\text {th }}$ Street has the same characteristics, but the reduction in capacity is 
Table 2 Total latent demand, direction S-N

\begin{tabular}{ccccc}
\hline Period & Scenario 0 & Scenario 1 & Scenario 2 & Scenario 3 \\
\hline 07:00-07:15 & 0 & 0 & 0 & 246 \\
07:15-07:30 & 0 & 0 & 0 & 174 \\
07:30-07:45 & 0 & 0 & 0 & 147 \\
07:45-08:00 & 0 & 0 & 5 & 175 \\
Total & 0 & 0 & 5 & 742 \\
\hline
\end{tabular}

Table 3 Total latent demand, direction N-S

\begin{tabular}{ccccc}
\hline Period & Scenario 0 & Scenario 1 & Scenario 2 & Scenario 3 \\
\hline 07:00-07:15 & 0 & 12 & 21 & 28 \\
07:15-07:30 & 0 & 0 & 2 & 102 \\
07:30-07:45 & 0 & 59 & 42 & 141 \\
07:45-08:00 & 0 & 113 & 89 & 248 \\
Total & 0 & 184 & 154 & 519 \\
\hline
\end{tabular}

lower. Table 2 and Table 3 show the latent demand in these approaches, for each scenario, in 15-minute intervals. In scenarios 0, 1 and 2, for S-N direction, we obtained a similar total latent demand. In the first two scenarios, there is a greater demand compared to the base scenario. In contrast, scenario 3 presents a considerable increase in latent demand when compared to the other scenarios. These results show that the lower the latent demand on the network, the greater capacity to support the flow.

For N-S direction, all the proposed scenarios have a higher latent demand value when compared to scenario 0 . The demand of scenarios 1 and 2 is close to the baseline scenario. In scenario 3 , as in the S-N direction, the demand compared to the base scenario, indicates a lower capacity of the network to support the flow.

\section{Demand of public transport vehicles}

Figure 10 shows the demand of public transport vehicles at the intersection approaches, for the three different scenarios. We report that the demand behaves totally different compared with the demand of total vehicles and we observe homogeneity between scenarios. Scenario 3 shows a behavior contrary to that of vehicles, in general, since the demand is greater in the S-N direction on $39^{\text {th }}$ Street than in the N-S direction on $45^{\text {th }}$ Street.

\section{Queue length}

Queue analysis allow us to evaluate if applied countermeasures are generating an increase in traffic congestion or an improvement in operating conditions. For this, queue lengths were measured at the entrance and exit of the study area. Maximum and mean queue lengths were analyzed to have a deeper understanding of the incidence of countermeasures.

Figure 11 shows that there is no relevant variation in the maximum queue length for the $\mathrm{S}-\mathrm{N}$ direction, for any

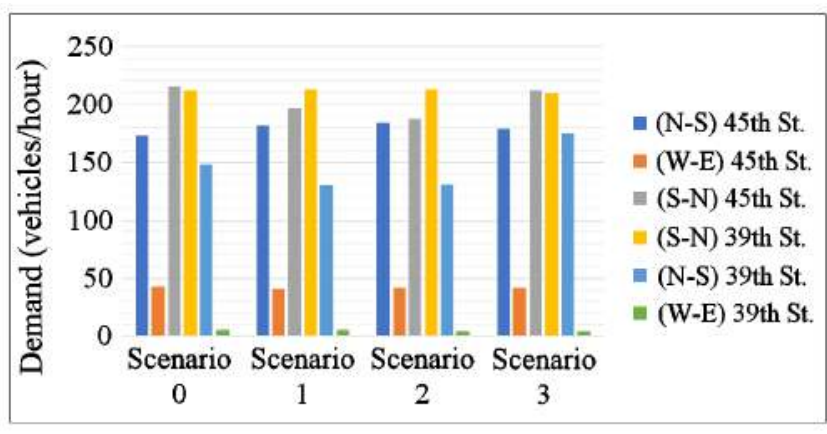

Figure 10 Demand of public transport vehicles

of the scenarios proposed. However, we report important increases in mean queue lengths if the countermeasures were applied, implying travel time increases, more congestion and worsening of level of service. N-S direction of the corridor shows similar behavior except for a great increase in mean and maximum queue length for the left-side segregated bus lane scenario, as shown in Figure 12.

\section{Traffic conflicts}

To validate the model, in terms of road safety, it is necessary to identify and describe the conflicts observed in the study area. The conflicts measurements were made from video data by a qualified team who identified and characterized the conflicts using STCT. This team of 8 undergraduate and graduate students in Civil Engineering received direct training from the author of the STCT, Christer Hydén, for the identification and characterization of traffic conflict, as well as in microsimulation of traffic conflicts in VISSIM and SSAM. Figure 13 shows the 18 lateral conflicts, that were identified in the field and classified as serious events. These conflicts will be compared with simulated conflicts.

Table 4 shows the number of conflicts extracted from the microsimulation models after ten different random runs of each scenario. In each scenario one simulation was selected as the most representative (highlighted in Table 4). The selected simulation in the base scenario was the one with the minor MAPE, implying a minor difference between observed and simulated conflicts. The analysis and comparison between observed and simulated conflicts are made based on lateral conflicts since these were the ones that we observed in the field. It is worth noting that in all proposed scenarios there is a clear decrease in the number of lateral conflicts, with the first scenario being the safest. The mean-square error (MSE) for the mean TTC, between the 10 runs, was calculated to identify the most representative run of the 3 scenarios, also highlighted in Table 4. 

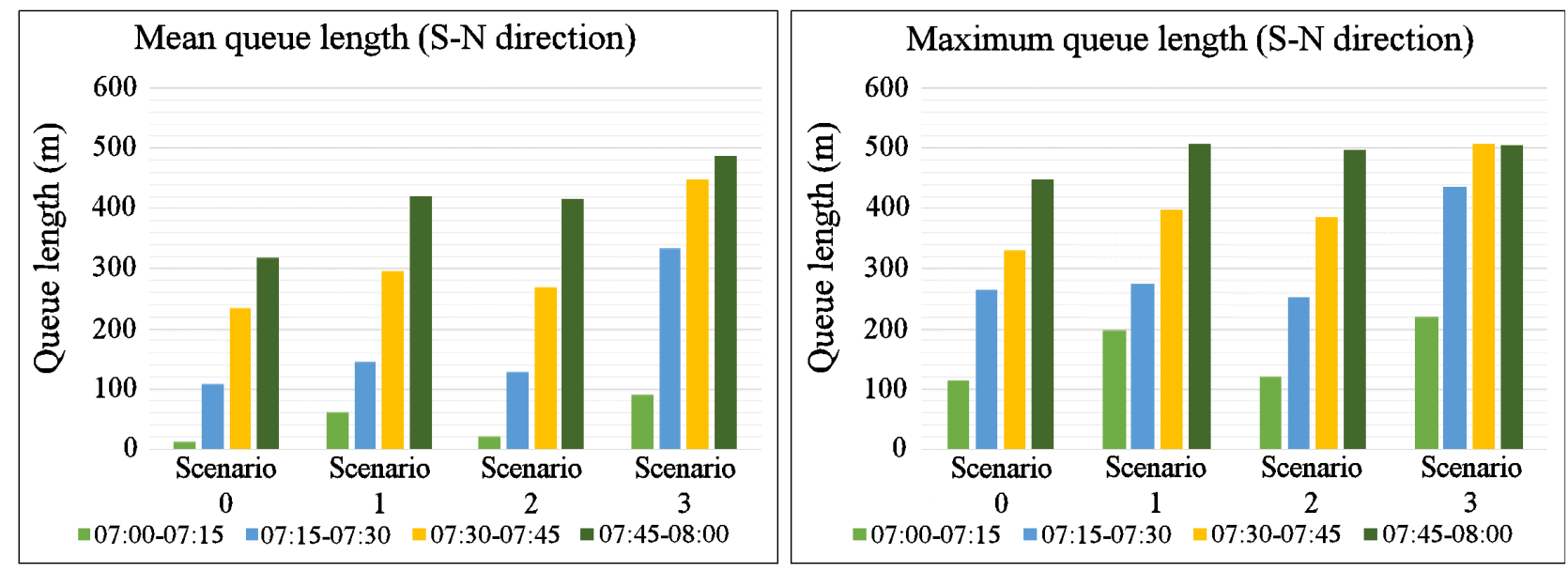

Figure 11 Maximum and mean queue lengths, S-N direction
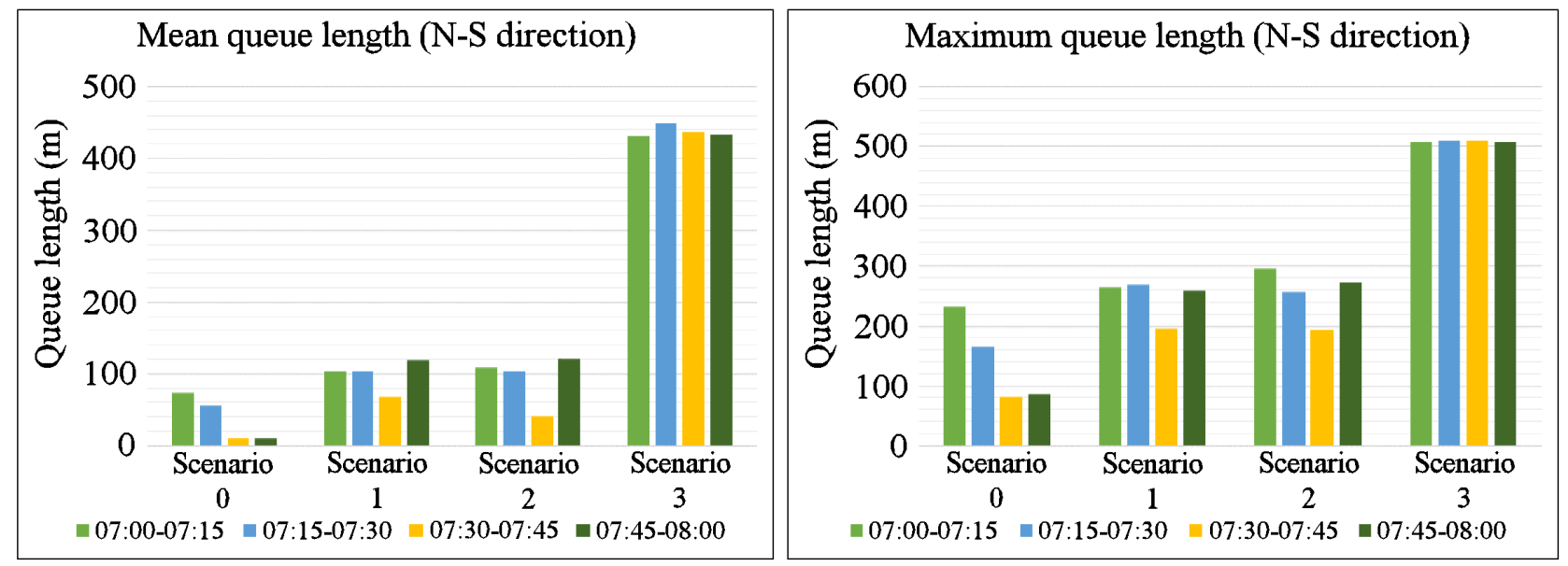

Figure 12 Maximum and mean queue lengths, N-S direction
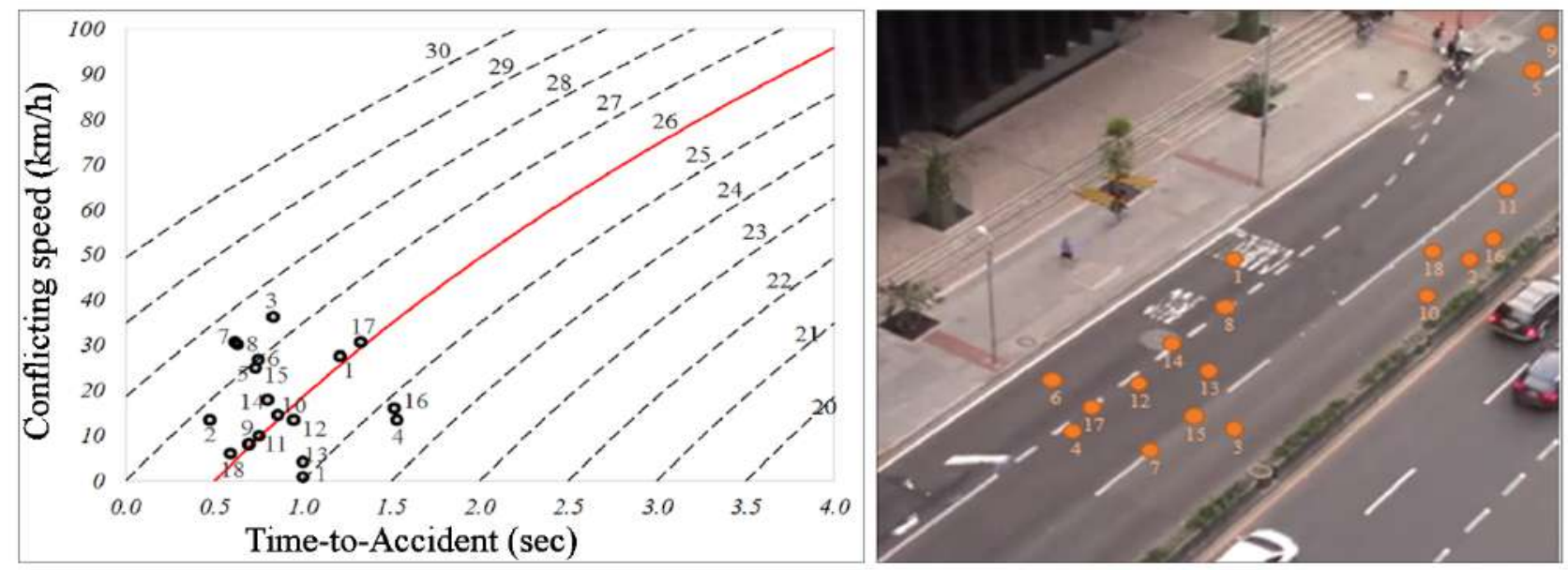

Figure 13 Observed traffic conflicts 
Table 4 Total number of conflicts for each scenario

\begin{tabular}{ccccccccccccc}
\hline Scenarios & $\mathbf{0}$ & & & $\mathbf{1}$ & & & $\mathbf{2}$ & & $\mathbf{3}$ & \\
\hline $\begin{array}{c}\text { Conflicts / } \\
\text { \# Simulation }\end{array}$ & Total & $\mathbf{L}$ & MAPE & Total & $\mathbf{L}$ & MSE & Total & $\mathbf{L}$ & MSE & Total & L & MSE \\
\hline 1 & 657 & 14 & $-22 \%$ & 286 & 3 & $41 \%$ & 430 & 3 & $-13 \%$ & 634 & 6 & $-1 \%$ \\
2 & 673 & 29 & $61 \%$ & 275 & 1 & $36 \%$ & 447 & 5 & $11 \%$ & 796 & 2 & $15 \%$ \\
3 & 537 & 16 & $-11 \%$ & 285 & 2 & $-2 \%$ & 383 & 3 & $79 \%$ & 727 & 4 & $-30 \%$ \\
4 & 637 & 16 & $-11 \%$ & 261 & 0 & $-100 \%$ & 433 & 1 & $-65 \%$ & 762 & 5 & $52 \%$ \\
5 & 542 & 26 & $44 \%$ & 230 & 1 & $51 \%$ & 538 & 7 & $36 \%$ & 691 & 3 & $-1 \%$ \\
6 & 587 & 22 & $22 \%$ & 235 & 1 & $-85 \%$ & 522 & 6 & $1 \%$ & 724 & 5 & $-24 \%$ \\
7 & 553 & 22 & $22 \%$ & 256 & 2 & $28 \%$ & 519 & 1 & $-48 \%$ & 717 & 9 & $4 \%$ \\
8 & 527 & 17 & $-6 \%$ & 226 & 1 & $51 \%$ & 451 & 3 & $-2 \%$ & 747 & 7 & $-11 \%$ \\
9 & 518 & 17 & $-6 \%$ & 261 & 1 & $51 \%$ & 459 & 4 & $0 \%$ & 744 & 6 & $-1 \%$ \\
10 & 634 & 22 & $22 \%$ & 264 & 1 & $-70 \%$ & - & - & - & 766 & 11 & $-3 \%$ \\
\hline Mean & $\mathbf{5 8 7}$ & $\mathbf{2 1}$ & - & $\mathbf{2 5 8}$ & $\mathbf{1}$ & - & $\mathbf{4 6 5}$ & $\mathbf{4}$ & - & $\mathbf{7 3 1}$ & $\mathbf{6}$ & - \\
\hline
\end{tabular}

Total: Total number of conflicts, L: lateral conflicts

\section{Surrogate safety measures}

The relationship between simulated surrogate measures, and the implications they have on the number and severity of traffic conflicts, is analyzed by means of linear regressions TTC vs PET, TTC vs MaxS, TTC vs DR and TTC vs Conflict angle, for the most representative run. This run, in scenarios 1, 2 and 3, was the one with the lowest mean-square-error, which were the third, ninth and ninth respectively as shown in Table 4. Also, the relationship between each of the variables and the probability of occurrence or severity of the conflict was taken into account [31].

Simulated conflicts obtained using SSAM, for the three countermeasures proposed, were obtained based on the initial conditions established in Table 5 from the base scenario. In the same way, the characteristics of the field-observed conflicts are used to improve the thresholds of each measure, also improving the simulation of conflicts.

Table 5 Thresholds set for simulated conflicts

\begin{tabular}{lcc}
\hline Measure & Min & Max \\
\hline Conflict Angle $\left.{ }^{\circ}\right)$ & 45 & 135 \\
TTC $(\mathrm{s})$ & 0.05 & 1.50 \\
PET $(\mathrm{s})$ & 0.00 & 5.00 \\
$\operatorname{MaxS}(\mathrm{m} / \mathrm{s})$ & 0.00 & 26.18 \\
DeltaS $(\mathrm{m} / \mathrm{s})$ & 0.00 & 25.650 \\
$\operatorname{DR}\left(\mathrm{m} / \mathrm{s}^{2}\right)$ & -8.38 & 3.5 \\
$\operatorname{MaxD}\left(\mathrm{m} / \mathrm{s}^{2}\right)$ & -8.38 & 3.5 \\
\hline
\end{tabular}

Previous research, [32-37] have characterized conflicts through surrogate safety measures denoting a level of risk, severity or speed. Table 6 shows the risk thresholds for five surrogate measures analyzed.

Table 6 Corridor qualification thresholds

\begin{tabular}{|c|c|c|c|}
\hline $\begin{array}{l}\text { Surrogate } \\
\text { Measure }\end{array}$ & Thresholds & Characterization & Reference \\
\hline TTC & $\begin{array}{l}\leq 0.9 \mathrm{~s} \\
>0.9 \mathrm{~s}\end{array}$ & $\begin{array}{c}\text { High Risk } \\
\text { Moderate Risk }\end{array}$ & [32] \\
\hline PET & $\begin{array}{l}<1.0 \mathrm{~s} \\
\geq 1.0 \mathrm{~s}\end{array}$ & $\begin{array}{c}\text { High Risk } \\
\text { Moderate Risk }\end{array}$ & [33] \\
\hline DR & $\begin{array}{l}<-3.0 \mathrm{~m} / \mathrm{s}^{2} \\
\geq-3.0 \mathrm{~m} / \mathrm{s}^{2}\end{array}$ & $\begin{array}{l}\text { High Severity } \\
\text { Low Severity }\end{array}$ & [34] \\
\hline Max S & $\begin{array}{l}>16.1 \mathrm{Km} / \mathrm{h} \\
<16.1 \mathrm{Km} / \mathrm{h}\end{array}$ & $\begin{array}{l}\text { High Speed Conflict } \\
\text { Low Speed Conflict }\end{array}$ & [35] \\
\hline Max DR & $\begin{array}{l}\leq-3.35 \mathrm{~m} / \mathrm{s}^{2} \\
>-3.35 \mathrm{~m} / \mathrm{s}^{2}\end{array}$ & $\begin{array}{l}\text { High Severity } \\
\text { Low Severity }\end{array}$ & [36] \\
\hline
\end{tabular}

Figure 14a shows linear regressions between TTC vs PET, the most commonly studied variables when working with SSAM. For the baseline scenario, as well as for alternative scenarios 2 and 3, a linear regression analysis can be done, given that data was obtained for more than two conflicts. However, for scenario 1, it is not possible to generate a trend by analyzing only data from two conflicts.

In [37], the relationship between "headway" and TTC in car following situation is exposed, that was later adapted as a relationship between PET and TTC in the same operational conditions in [31]. The latter generated the classification shown in Table 7. Although no classification was found for lateral conflicts, this is a good approximation to understand the possible events that can occur based on TTC and PET values and their relationship with the risk.

As seen in Figure 14a, there are no conflict data in the 
Table 7 Risk for TTC and PET [31]

\begin{tabular}{ccc}
\hline \multirow{2}{*}{ TTC } & \multicolumn{2}{c}{ PET } \\
\cline { 2 - 3 } & Small & Large \\
\hline Small & Danger imminent & Impossible \\
Large & Potential danger & Safe \\
\hline
\end{tabular}

upper left part of the graph. This area corresponds to high PET values and low TTC values, which in practice are difficult to find. This is because conceptually [23] PET is the time that elapses from the encroachment of the trajectory until the invaded vehicle reaches the conflict point, and TTC is the theoretical value of the time to an eventual collision under given conditions of speed and distance. Then, if the time after the encroachment is high, it is difficult that along this there is a critical value under a theoretical TTC. It can be observed that, in general, the application of countermeasures results in the existence of conflicts that have higher values of TTC and PET, implying a lower probability of occurrence. In Figure 14a to Figure $14 \mathrm{~d}$, linear models were used to verify if the trend presented by the surrogate measures of the simulated conflicts corresponds to the expected trend according to the theory.

In the case of the evaluations carried out in the model for TTC vs MaxS, shown in Figure 14b, there is no high correlation between the variables with values of $R^{2}$ that do not reach 0.5. However, in the base scenario and scenario 1 , a slight negative trend is shown in the slope, while in scenario 3, a positive trend is observed. Associating MaxS with the severity of the conflict, we report that the three proposed operational configurations considerably reduce the number of conflicts with MaxS greater than $5[\mathrm{~m} / \mathrm{s}]$, which implies less possible severity on them. However, among the 3 scenarios proposed, no great difference is observed.

In the case of TTC vs DR, only for the case of scenario 2, a certain correlation is observed with a slight negative slope in the regression line, as shown in Figure 14c. The deceleration parameter increases in magnitude for the proposed countermeasures, which would imply a higher probability of occurrence of a conflict. This may be since, in a more orderly flow, due to segregation or the strict application of the norm, higher speeds may be presented at the moment of trajectory encroachment, implying greater decelerations. This analysis contrasts with what was found for the variable MaxS, in which a decrease in the maximum speed was reported in the conflicts for the proposed scenarios.

No correlation was found between TTC vs. Conflict angle (Figure $14 \mathrm{~d}$ ). Although, no literature has been found regarding this analysis, one can detect a large decrease in the angle in which conflicts occur. This is related to the decrease in lane changes of the vehicular interaction that is expected to occur in all the proposed scenarios.

\section{Scenario analysis}

According to Table 8, the first proposed scenario would not have improvement over traffic operating conditions. However, in terms of road safety one can expect great benefits, since the number of conflicts decreases substantially from 17 to 2 . As for the severity of those conflicts, it is observed that it is similar, except in terms of deceleration, which increases, and in terms of speed, which decreases. For an improvement of the first scenario, stronger regulations are required, defining stop time of private vehicles and taxis on the preferential lane. This could also improve the operation of the preferential lane and avoid conflicts as a result of the transit of buses to the second lane. Additionally, the need to control on-street parking is evident, since, as observed in the field, this regulation is not presented.

For the second scenario, which considers the physical segregation of the external preferential lane, except at bus stops to allow overtaking, the number of conflicts decreases from 17 to 4 . Latent demand and public transport decreases in all senses with respect to the base scenario, except for the latent demand from north to south that increases. For this scenario, queues and deceleration increased in both directions compared to the base scenario, but speeds decrease.

The third proposed scenario has a lower capacity to support the flow because it presents a higher latent demand, which causes queue lengths to increase considerably. Of the three proposed scenarios, this is the one that reports the greatest number of conflicts when compared to the base scenario (6 conflicts). For this case, the deceleration increases, and the speed decreases when compared to scenario 0 . Considering that physical segregation is proposed for the second and third scenarios, we expect higher interaction between vehicles, because of the decrease in capacity of mixed lanes.

\section{Conclusions}

We propose and validate a methodology to link field studies of traffic conflicts and the microsimulation of such events, showing that it is also possible to validate a simulation modeling based on traffic and safety variables. Under the calibrated environment, three scenarios of operational changes were simulated seeking to improve safety indicators. After this procedure, different parameters were established, and we propose them to be used as a 

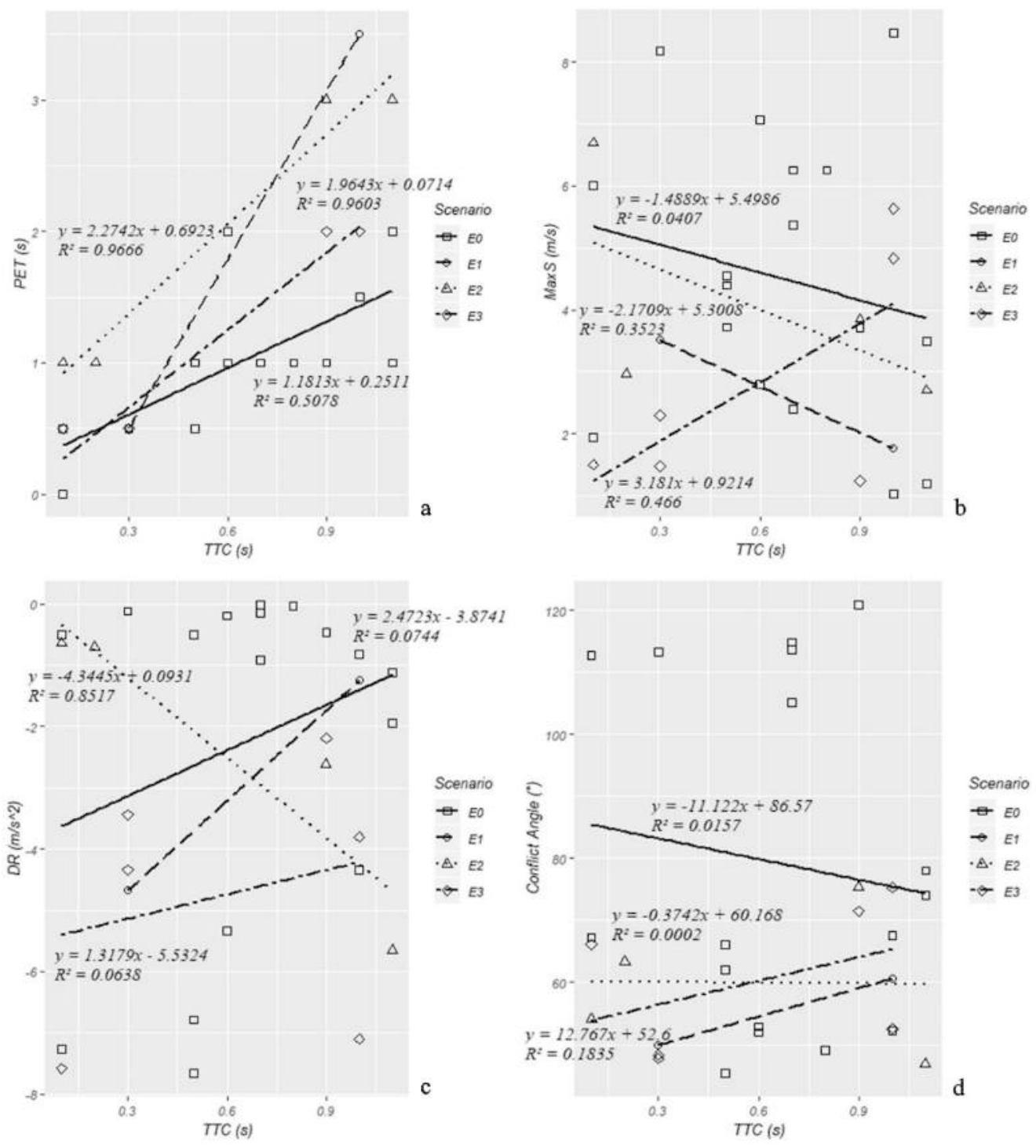

Figure 14 Relationships between surrogate safety measures and conflict angle

starting point in future local road safety studies based on conflicts.

The implementation of the preferential lane of $7^{\text {th }}$ Avenue has a positive influence on road safety conditions along this corridor, reducing conflicts and potential accidents. However, only when the preferential lane operates according to the existing regulations (scenario 1) improvements are observed. We did not observe such behavior in the field. There were 18 conflicts observed in the field and only 2 can be observed when simulating the operation established in the regulations, corresponding to scenario 1.

The configuration of alternative scenarios of exclusive and/or preferential bus lanes also improve road safety, in terms of traffic conflicts and surrogate safety measures. The above is concluded from the number of conflicts obtained in scenario 2 (4) and scenario 3 (6). The mean values of the surrogate measures studied indicate a safer general operation in scenario 1, validating the regulation. This is caused by the reduction on the number of encroaching vehicles of the bus lane; therefore, fewer events between public transport and private vehicles are expected. Additionally, an adjustment is recommended in the normative measures, including regulating the stopping time and stopping zones of private vehicles and taxis letting for further research the study of acceptable stop times.

For the initial calibration process, there were some parameters avoided due to high uncertainty in data 
Table 8 Parameters compared between scenarios

\begin{tabular}{lcccc}
\hline Scenario & $\mathbf{0}$ & $\mathbf{1}$ & $\mathbf{2}$ & $\mathbf{3}$ \\
\hline Latent demand S-N (vehicles) & - & 64 & 31 & -742 \\
Latent demand N-S (vehicles) & - & -172 & -154 & -519 \\
Public transport demand S-N (vehicles) & 427 & 410 & 400 & 421 \\
Public transport demand N-S (vehicles) & 321 & 312 & 316 & 354 \\
Queue length S-N(m) & 289.5 & 344.3 & 314.2 & 417.4 \\
Queue length N-S(m) & 232.8 & 268.5 & 296.6 & 509.2 \\
Conflicts number & 17 & 2 & 4 & 6 \\
TCC min mean $(\mathrm{s})_{\text {PET mean }(\mathrm{s})}$ & $0.6588(\mathrm{HR})$ & $0.6500(\mathrm{HR})$ & $0.5760(\mathrm{HR})$ & $0.6072(\mathrm{HR})$ \\
DR mean $\left(\mathrm{m} / \mathrm{s}^{2}\right)$ & $1.0294(\mathrm{MR})$ & $2.0000(\mathrm{MR})$ & $1.7899(\mathrm{MR})$ & $1.1810(\mathrm{MR})$ \\
Max DR mean $\left(\mathrm{m} / \mathrm{s}^{2}\right)$ & $-2.2453(\mathrm{LS})$ & $-2.9650(\mathrm{LS})$ & $-3.0544(\mathrm{HS})$ & $-3.6717(\mathrm{HS})$ \\
Max S mean $(\mathrm{m} / \mathrm{s})$ & $-2.9124(\mathrm{LS})$ & $-4.0250(\mathrm{HS})$ & $-5.0013(\mathrm{HS})$ & $-5.0117(\mathrm{HS})$ \\
Delta S mean $(\mathrm{m} / \mathrm{s})$ & $4.5176(\mathrm{HSC})$ & $2.6400(\mathrm{LSC})$ & $4.1842(\mathrm{LSC})$ & $2.9617(\mathrm{LSC})$ \\
\hline
\end{tabular}

Note: HR: High Risk, LR: Low Risk, MR: Moderate Risk, HS: High Severity, LS: Low Severity, HSC: High Speed Conflict, LSC: Low Speed Conflict (Variable characterization based on Table 6).

collection. Queue lengths are considered volatile parameters [28] and also not appropriate for this study because of the difficulty in counting the number of vehicles in queue or measuring its length when using video data. Those difficulties were mainly due to high distance between the data collection point and the intersections observed. However, the simulated queue lengths were used to evaluate the operational effect of the proposed countermeasures. In this sense, it was evidenced that the use of the bus lane under the regulations does not represent a deterioration of the operation. Travel times were also discarded owing to the difficulties to identify the vehicles circulating along the corridor as a consequence of the camera quality and the distance. The hypothesis of high uncertainty in these variables were confirmed with statistical analysis such as standard deviation which shows a high variability between the data collected. For this reason, these variables were not considered from the beginning of the project. The variables used represent the reliability and certainty of the model. The analyses were carried out with the most representative simulation run, which was the one where the greatest number of conflicts is presented from lane 1 to lane 2.

Some other limitations were found in the research process. Obtaining traffic conflicts information from video data was done using the STCT. In this case it was possible to measure values of Conflicting Speed (CS) and distance to obtain Time to Accident (TA). However, the measures obtained from SSAM were minimum TTC, PET, DR, among others. Software SSAM is not able to measure TA, because it cannot detect where an evasive manoeuvre has initiated. So, second step calibration was performed comparing field-measured TA values with TTC $_{\min }$ calculated by SSAM.

\section{Acknowledgments}

The authors thank Universidad Nacional de Colombia, for the financial support through the "Convocatoria nacional de proyectos para el fortalecimiento de la investigación, creación e innovación de la Universidad Nacional de Colombia 2016-2018" to perform this research project.

\section{References}

[1] World Health Organization, "Global status report on road safety 2015," World Health Organization, Tech. Rep., 2015.

[2] INMLCF. (2018, May) Forensis 2017 datos para la vida. Accessed Feb. 15, 2018. [Online]. Available: http: //www.medicinalegal.gov.co/documents/20143/262076/Forensis+ 2017+Interactivo.pdf/0a09fedb-f5e8-11f8-71ed-2d3b475e9b82

[3] J. Schuppan, S. Kettner, A. Delatte, and O. Schwedes, "Urban multimodal travel behaviour: Towards mobility without a private car," Transp. Res. Procedia, vol. 4, pp. 553-556, 2014.

[4] X. Ye and W. Ma, "Influence of access traffic on the operational efficiencies of bus lane and main road," Procedia - Soc. Behav. Sci., vol. 96, no. 6, pp. 1648-1658, Nov. 2013.

[5] H. B. Zhu, "Numerical study of urban traffic flow with dedicated bus lane and intermittent bus lane," Phys. A Stat. Mech. its Appl., vol. 389, no. 16, pp. 3134-3139, Aug. 2010.

[6] J. Viegas and B. Lu, "Traffic control system with intermittent bus lanes," IFAC Transp. Syst. Proc. Vol., vol. 30, no. 8, pp. 865-870, Jun. 1997.

[7] B. Ahmed, "Exploring new bus priority methods at isolated vehicle actuated junctions," Transp. Res. Procedia, vol. 4, pp. 391-406, 2014.

[8] J. Viegas, B. Lu, J. Vieira, and R. Roque, "Demonstration of the intermittent bus lane in lisbon," IFAC Proc. Vol., vol. 11, pp. 239-244, 2006.

[9] A. Laureshyn, M. de Goede, N. Saunier, and A. Fyhri, "Cross-comparison of three surrogate safety methods to diagnose cyclist safety problems at intersections in norway," Accid. Anal. Prev., vol. 105, pp. 11-20, Aug. 2017.

[10] F. G. Habtemichael and L. de Picado, "Crash risk evaluation of aggressive driving on motorways: Microscopic traffic simulation 
approach," Transp. Res. Part F-Traffic Psychol. Behav., vol. 23, pp. 101-112, Mar. 2014.

[11] T. Giuffre, S. Trubia, A. Canale, and B. Persaud, "Using microsimulation to evaluate safety and operational implications of newer roundabout layouts for european road networks," Sustain., vol. 9, no. 11, pp. 1-13, 2017

[12] K. C. K. Goh, G. Currie, M. Sarvi, and D. Logan, “Bus accident analysis of routes with/without bus priority," Accid. Anal. Prev., vol. 65, pp. 18-27, Apr. 2014.

[13] P. Guest, "13-public transport priority," in Traffic Engineering Design: Principles and Practice, M. Slinn, P. Matthews, and P. Guest, Eds. Butterworth-Heinemann, 2005, pp. 166--179.

[14] Y. Chen, G. Chen, and K. Wu, “Evaluation of performance of bus lanes on urban expressway using paramics micro-simulation model," Procedia Eng., vol. 137, pp. 523-530, 2006.

[15] H. J. Kim, "Performance of bus lanes in seoul: Some impacts and suggestions," IATSS Res., vol. 27, no. 2, pp. 36-45, 2003.

[16] F. Xu, Y. Du, and L. Sun, "A framework for ongoing performance monitoring of bus lane system," Procedia - Soc. Behav. Sci., vol. 96 , pp. 175-181, Nov. 2013.

[17] J. Viegas and B. Lu, "The intermittent bus lane signals setting within an area," Transp. Res. Part C Emerg. Technol., vol. 12, no. 6, pp. 453-469, 2004

[18] N. Clabaux, J. Y. Fournier, and J. E. Michel, "Powered two-wheeler drivers' crash risk associated with the use of bus lanes," Accid. Anal. Prev., vol. 71, pp. 306-310, Oct. 2014.

[19] T. de Ceunynck and et al., "Sharing is (s)caring? interactions between buses and bicyclists on bus lanes shared with bicyclists," Transp. Res. Part F Traffic Psychol. Behav., vol. 46, no. part B, pp. 301-315, Apr. 2017.

[20] K. C. K. Goh, G. Currie, M. Sarvi, and D. Logan, "Experimental microsimulation modeling of road safety impacts of bus priority," Transp. Res. Rec. J. Transp. Res. Board, vol. 2402, no. 1, pp. 9-18, 2014.

[21] F. Huang, P. Liu, H. Yu, and W. Wang, "Identifying if VISSIM simulation model and SSAM provide reasonable estimates for field measured traffic conflicts at signalized intersections," Accid. Anal. Prev., vol. 50, pp. 1014-1024, Jan. 2013.

[22] C. Hyden, "he development of a method for traffic safety evaluation: the swedish traffic conflict technique," Bulletin Lund University of Technology, vol. 70, 1987.

[23] C. Johnsson, A. Laureshyn, and T. D. Ceunynck, "In search of surrogate safety indicators for vulnerable road users: a review of surrogate safety indicators," Transport Reviews, vol. 38, no. 6, pp. $1-21,2018$

[24] A. Svensson, "A method for analysing the traffic process in a safety perspective," Ph.D. Dissertation, Lund Institute of Technology, Dept. of Traffic Planning and Engineering, Lund, Sweden, 1998.

[25] D. Gettman and L. Head, "Surrogate safety measures from traffic simulation models, final report," U. S. Department of Transportation. Federal Highway Administration, McLean, Virginia, Tech. Rep. FHWA-RD-03-050, Jan. 2003.

[26] Secretaría Distrital de Movilidad. (2018) Información sobre accidentalidad. Accessed Jun. 13, 2018. [Online]. Available: http:// movilidadbogota.maps.arcgis.com/apps/webappviewer/index.html

[27] IDECA. (2018) Mapas de referencia unidad administrativa especial de catastro distrital. Accessed Apr. 05, 2018. [Online]. Available: https://www.ideca.gov.co/es/servicios/ mapa-de-referencia/tabla-mapa-referencia

[28] NZ Transport Agency. (2014, Apr. 1) Transport model development guidelines. [Online]. Available: https://www.nzta.govt.nz/assets/ resources/transport-model-development-guidelines/docs/tmd. pdf

[29] S. Zhou, J. Sun, X. An, and K. Li, "The development of a conflict hazardous assessment model for evaluating urban intersection safety," Transport, vol. 26, no. 2, pp. 216-223, 2011.

[30] Resolución 560, Alcaldía Mayor de Bogotá, Bogotá, Colombia, 2015.

[31] N. Nadimi, H. Behbahani, and H. Shahbazi, "Calibration and validation of a new time-based surrogate safety measure using fuzzy inference system," J. Traffic Transp. Eng., vol. 3, no. 1, pp. 51-58, Feb. 2016.

[32] T. Sayed and S. Zein, "Traffic conflict standards for intersections," Transp. Plan. Technol., vol. 22, no. 4, pp. 309-323, Aug. 1999.

[33] J. Archer and I. Kosonen, "The potential of micro-simulation modelling in relation to traffic safety assessment," in ESS Conference Proceedings, Hamburg, Germany, 2000, pp. 1-6.

[34] M. R. C. McDowell, J. Wennell, P. A. Storr, and J. Darzentas, “Gap acceptance and traffic conflict simulation as a measure of risk," Transport and Road Research Laboratory (TRRL), vol. 776, pp. 1-19, 1983.

[35] D. Gettman, L. Pu, T. Sayed, and S. Shelby, "Surrogate safety assessment model and validation: Final report," U.S. Department of Transportation. Federal Highway Administration, McLean, VA, Tech. Rep. FHWA-HRT-08-051, Jun. 2008.

[36] J. Archer, "Methods for the assessment and prediction of traffic safety at urban intersections and their application in micro-simulation modelling," M.S. thesis, Royal institute of technology, Stockholm, Sweden, 2004.

[37] K. Vogel, "A comparison of headway and time to collision as safety indicators," Accid. Anal. Prev., vol. 35, no. 3, pp. 427-433, May 2003. 